\title{
O ATO DE LER NA PEDAGOGIA HISTÓRICO-CRÍTICA E SUAS POSSIBILIDADES NA EDUCAÇÃO BÁSICA
}

\author{
Geuciane Felipe Guerim Fernandes \\ Sandra Aparecida Pires Franco
}

Resumo

Este estudo está vinculado aos resultados finais de uma pesquisa de Pós Graduação, stricto sensu (Mestrado), que teve como objetivo principal analisar se a ação docente, fundamentada no Materialismo HistóricoDialético e na Pedagogia Histórico-Crítica, é fundamental para o desenvolvimento do ato de ler na Educação Básica. Nesse texto, analisou-se o processo de intervenção vivenciado pelos professores e alunos participantes da pesquisa. Ao materializar os fundamentos da Pedagogia Histórico-Crítica para o ato de ler e para a leitura literária, buscou-se vislumbrar um ensino que garanta aos nossos alunos o direito inalienável aos bens culturais produzidos pela humanidade, para que, por intermédio do conhecimento, possam desenvolver-se e, com isso, humanizar-se, no sentido de compreender as contradições da sociedade e intervir sobre elas, edificando a prática social como sujeito construtor da história humana.

Palavras-chave: pedagogia histórico-crítica; ato de ler; prática social; educação básica.

\section{THE ACT OF READING IN HISTORICAL-CRITICAL PEDAGOGY AND ITS POSSIBILITIES IN BASIC EDUCATION}

\begin{abstract}
This study is linked to the final results of a Postgraduate research, stricto sensu (Master's degree), whose main objective was to analyze if the teaching action, based on Historical-Dialectical Materialism and HistoricalCritical Pedagogy, is fundamental for the development of reading in basic education. In this paper, we analyzed the intervention process experienced by teachers and students participating in the research. In materializing the foundations of Historical-Critical Pedagogy for reading and literary reading, we sought to envisage teaching that guarantees students the inalienable right to cultural goods produced by humanity, so that through the knowledge they can develop. In order to understand the contradictions of society and intervene over them, building up social practice as the constructive subject of human history.
\end{abstract}

Keywords: historical-critical pedagogy; the act of reading; social practice; primary education.

\section{EL ACTO DE LEER EN LA PEDAGOGÍA HISTÓRICO-CRÍTICA Y SUS POSIBILIDADES EN LA EDUCACIÓN BÁSICA}

Resumen

Este estudio está vinculado a los resultados finales de una investigación de Postgrado, stricto sensu (Maestría), que tuvo como objetivo principal analizar si la acción docente, fundamentada en el Materialismo HistóricoDialéctico y en la Pedagogía Histórico-Crítica, es fundamental para el desarrollo del "el acto de leer en la Educación Básica. En este texto, se analizó el proceso de intervención vivido por los profesores y alumnos participantes de la investigación. Al materializar los fundamentos de la Pedagogía Histórico-Crítica para el acto de leer y para la lectura literaria, se buscó vislumbrar una enseñanza que garantice a nuestros alumnos el derecho inalienable a los bienes culturales producidos por la humanidad, para que, por intermedio del conocimiento, puedan desarrollarse y, con ello, humanizarse, en el sentido de comprender las contradicciones de la sociedad e intervenir sobre ellas, edificando la práctica social como sujeto constructor de la historia humana..

Palabras clave: pedagogía histórico-crítica; acto de lectura; práctica social; educación básica. 


\section{INTRODUÇÃO}

Dentro do livro "[...] tem partida, tem viagem, tem estrada, tem caminho, tem procura, tem destino, lá dentro do livro" (AZEVEDO, 1998). É assim que Ricardo Azevedo (1998) inicia o poema "Dentro do Livro", traduzindo em versos a riqueza e beleza vivenciada com o ato de ler. A escolha por este poema traduz o próprio movimento realizado por este estudo, o ato de ler como viagem, estrada, caminho, procura e destino, superação e um novo posicionamento frente à realidade.

O estudo proposto está vinculado aos resultados de uma pesquisa de pós-graduação stricto sensu (Mestrado), que teve como objetivo principal analisar se a ação docente, fundamentada no Materialismo Histórico-Dialético e na Pedagogia Histórico-Crítica, é fundamental para o desenvolvimento do ato de ler na Educação Básica. A pesquisa foi direcionada à luz da perspectiva crítico-dialética, no sentido de abordar os aspectos da realidade estudada em sua totalidade, tendo como estratégia a pesquisa-ação.

Como público alvo, contamos com a participação de dois docentes de Língua Portuguesa e suas respectivas turmas do $1^{\circ}$ ano do Ensino Médio de uma instituição de ensino vinculada ao Projeto OBEDUC. Para a coleta de dados, foram utilizados questionários iniciais e finais junto aos professores participantes, um Grupo de Estudos e, posteriormente, intervenções em sala de aula, que serão instrumentos de análise neste trabalho.

O trabalho realizado buscou apresentar uma nova possibilidade de conduzir o trabalho educativo, porém, apropriar-se de uma concepção de mundo materialista histórica e dialética, pressupõe a difusão desta concepção de mundo ao longo do processo de escolarização.

\section{O ATO DE LER: UMA PROPOSTA DE INTERVENÇÃO PARA O DESENVOLVIMENTO HUMANO}

A Pedagogia Histórico-Crítica defende como papel da escola, identificar os elementos que precisam ser assimilados pelos alunos e, concomitantemente, desenvolver formas adequadas para sua apropriação. Apropriando-se dessa concepção, trataria de incorporar este conhecimento à realidade social, ou seja, reconstruir diretrizes que possibilitam a reorganização do trabalho educativo, conteúdos, procedimentos que darão início a um novo movimento de desenvolvimento educativo, objetivando uma nova sociedade e um novo homem.

Assim, o Grupo de Estudos realizado junto aos professores foi direcionado visando superar as concepções iniciais dos professores para que, por meio dos estudos e abstrações, pudessem perceber a realidade enquanto uma totalidade construída pelos homens e a leitura como prática social inerente nesse processo e instrumento de luta e combate a alienação. Os objetivos delineados em cada encontro possibilitaram o direcionamento da pesquisa e dos sujeitos para o percurso metodológico do próprio método dialético, que nas palavras de Gasparin (2012, p. X), consiste em "[...] partir da prática, ascender à teoria e descer novamente á prática, não já como prática inicial, mas como práxis, unindo contraditoriamente, de forma inseparável, a teoria e a prática em um novo patamar de compreensão da realidade e de ação humana".

Movidos pela prática inicial, propusemos aos professores a realização de um Grupo de Estudos fundamentados no Materialismo Histórico-Dialético e na Pedagogia Histórico-Crítica, para que em seguida, por meio da proposta Didática desenvolvida por Gasparin (2012), fosse possível retornar à pratica social, elaborando um planejamento docente-discente sobre o ato de ler, tendo como objeto a leitura literária. 
Contamos com as contribuições de Gasparin (2012) para viabilizarmos uma possibilidade do ato de ler em sala de aula, buscando traduzir e efetivar os cinco passos da Pedagogia HistóricoCrítica (prática social, problematização, instrumentalização, catarse, retorno à prática social) e o próprio movimento do Materialismo Histórico-Dialético, o que nas palavras de Gasparin (2012, p. 3) se traduz em "[...] caminhar da realidade social, como um todo, para a especificidade teórica da sala de aula e desta para a totalidade social novamente, tornando-se possível um rico processo dialético de trabalho pedagógico".

Assim, a elaboração e execução do planejamento docente-discente foram inspiradas nos estudos da obra "Uma Didática para a Pedagogia Histórico-Crítica", a partir de uma nova perspectiva sobre o processo de ensino e aprendizagem, interligando a prática social do aluno e as questões sociais mais amplas aos conhecimentos já produzidos pela humanidade, em uma relação dialética. A prática social se constitui como ponto de partida e de chegada da prática educativa. Assim, o trabalho educativo realiza um processo de mediação, que busca por meio do conhecimento historicamente acumulado, possibilitar aos alunos a superação de uma inserção acrítica para uma inserção crítica e intencional na prática social (OLIVEIRA; DUARTE, 1986; SAVIANI, 2008; 2011). Assim, a Didática de Gasparin (2012) constituiu-se uma possibilidade de forma, a literatura uma possibilidade de conteúdo e a ação docente o compromisso intencional com o conhecimento para a mediação do ato de ler.

Após as leituras e análises, os professores elaboraram cuidadosamente o planejamento, que resultaria na efetivação dos estudos e na própria síntese de que haviam se apropriado do conhecimento apreendido. $\mathrm{Na}$ busca por uma práxis transformadora, professores e alunos tornaram-se sujeitos ativos na pesquisa, tanto nos estudos como nas próprias análises realizadas durante as aulas.

Pela mediação dos professores, foi realizado um trabalho com os alunos com o conteúdo "Leitura Literária". Utilizou-se como instrumento inicial uma música de Chico Buarque, intitulada "Cálice", para sensibilizar os alunos quanto ao conteúdo que seria trabalhado e, após o trabalho com a música, os professores utilizaram um conto literário "Holocausto" de Caio Fernando de Abreu, como instrumento de leitura que possibilita a análise e compreensão da realidade social. Como síntese, os alunos puderam elaborar seus próprios contos, possibilitando-os a efetivação do ato de ler.

Para o tópico do conteúdo trabalhado neste texto, os professores destacaram como objetivo analisar o conto "Holocausto" e o contexto de sua produção, no intuito de perceber as dimensões: conceitual, histórica, social, cultural, política, legal, afetiva, psicológica, estética, entre outras, que estão postas na leitura e na sociedade. Como instrumentalização os professores utilizaram exposição oral e análise do texto literário "Holocausto".

Ao propor a leitura literária em sala de aula, o professor viabiliza ao aluno oportunidades de análise e síntese (descoberta de ideias principais do texto, coordenação, estrutura da obra, entre outros aspectos). Luria et al. (2007) aponta ser este um momento de passagem para uma nova atividade escolar, convertendo-se para o aluno como instrumento de memória, abstração, generalização conduzindo-o ao desenvolvimento da curiosidade, iniciativa e independência frente ao conhecimento trabalhado. Ainda segundo os autores, conduzir o desenvolvimento humano pressupõe organizar este movimento de interação e "[...] dirigir a atividade do aluno para o conhecimento da realidade e para o domínio - por meio da palavra - do saber da cultura da humanidade [...]". (LURIA et al., 2007, p. 44).

Com a mediação docente, o social se converte em subjetivo - ou seja - individual, e assim, o aluno organiza a sua própria atividade, desenvolvendo novas funções psíquicas. A fim de observarmos este processo, transcrevemos alguns momentos das intervenções realizadas durante 
a pesquisa, a fim de perceber se o método proposto constitui uma possibilidade efetiva para o ato de ler em sala de aula.

Para dar início ao tópico do conteúdo, na turma A, o professor acalma os alunos e prepara o ambiente para a leitura.

PA: Nós vamos ler agora um conto chamado "Holocausto". Vocês já ouviram falar dessa palavra Holocausto?

A1: Sim, nas guerras.

PA: Por que o primeiro significado que vem na cabeça de vocês é a guerra? Porque vocês já estudaram as Guerras. Mas tem um primeiro significado antes desse. O primeiro significado de Holocausto vem de Sacrifício. Os Hebreus ofereciam sacrifícios de animais para Deus, os animais eram sacrificados e queimados oferecidos como sacrifício. Depois nós temos o Holocausto lá na $2^{\mathrm{a}}$ Guerra e hoje nós vamos fazer outra relação desse holocausto com aquilo que nós estudamos semana retrasada.

A2: Com a ditadura?

PA: Isso muito bem. Nós vamos tentar perceber este Holocausto da Ditadura dentro desse texto que nós vamos fazer a leitura agora. Eu quero que vocês tentem identificar se o título do texto faz relação com o conteúdo do conto. (INFORMAÇÃO VERBAL) ${ }^{1}$

Após instigar os alunos para o título do conto, o professor A propõe a leitura silenciosa e, em seguida, estabelece com a turma diversas dimensões presentes no conto e que podem auxiliar na compreensão desse todo. Para iniciar, o professor apresenta o autor do conto e contextualiza o momento histórico.

PA: Uma dica para compreendermos este texto é compreendermos o autor do texto. Esse autor aqui viveu esse momento da ditadura militar. Este sofrimento que ele narra tem tudo a ver com o sofrimento que ele também passou durante a ditadura. E o que as pessoas sentiam naquele momento? Desespero, agonia, medo, solidão, pois não sabiam o amanhã de sua vida, de sua família. (INFORMAÇÃO VERBAL).

No mesmo tópico, o professor B anuncia que irão realizar a leitura silenciosa de um conto, os alunos vão aos poucos se acalmando e no olhar percebemos a curiosidade sobre o texto. Entendemos que esta curiosidade percebida nos alunos está relacionada ao próprio movimento realizado pelo conto, pelos olhos fixados nas palavras fortes e de impacto que propõe o texto. Manguel (1997) afirma que a leitura realizada em particular está livre de orientações e esclarecimentos, os olhos por si revelam sentidos individuais em uma comunicação sem testemunhas. Em seguida, o professor B apresenta o autor do texto, o período que viveu durante a ditadura militar e aponta que o conto foi escrito durante este período.

PB: Por que esse nome Holocausto?

B1: Um apagão?

PB: Esse holocausto vem de sacrifício. $\mathrm{Na}$ época dos hebreus era utilizado para nomear uma série de sacrifícios, praticados pelos antigos Hebreus em homenagem aos deuses, onde o sacrifício era totalmente queimado.

PB: $\mathrm{O}$ que vocês sentiram ao ler o conto?

B1: Medo

\footnotetext{
1 Transcrição direta de aula realizada durante as intervenções.
} 


\section{B2: Suspense}

B3: Mal estar

PB: Vocês viram como o Caio Fernando de Abreu é detalhista ao falar dos personagens, sobre o piolho, a dor, as feridas. A situação das pessoas ali era muito difícil, eles foram queimando tudo o que tinha na casa, até que uma hora não tinha mais nada, então eles começaram a se sacrificar. O Caio Fernando de Abreu viveu na época da Ditadura militar, então, assim como falamos do Chico Buarque, ele também foi exilado. Ele retrata o massacre dos jovens por não ter liberdade de expressão, ele retrata toda a repressão da época e neste conto mostra o sofrimento das pessoas. (INFORMAÇÃO VERBAL) ${ }^{2}$

O professor B diz brevemente aos alunos que o conto apresenta dimensões sociais, políticas, ideológicas e faz a leitura das questões da problematização conforme exposto no plano de trabalho docente-discente. Após este processo vivenciado em ambas as turmas, os professores propuseram uma avaliação do conteúdo apreendido, conforme o seguinte enunciado:

Se você tivesse que escrever um conto, retratando um problema social, sobre o que escreveria? Desenvolva um conto que retrate um problema, como o apresentado no conto "Holocausto" (solidão, medo, insegurança, entre outros), utilizando as dimensões trabalhadas (histórica, econômica, social, cultural, ideológica, de poder, política, estética, afetiva, ética, entre outras), relacionando com questões dos dias atuais. (GRUPO DE ESTUDOS, PLANEJAMENTO DE TRABALHO DOCENTE-DISCENTE) ${ }^{3}$

Para tanto, buscou-se "[...] desenvolver o pensamento nos alunos, a sua capacidade de analisar e generalizar os fenômenos da realidade, de raciocinar corretamente; resumindo, desenvolver 'no todo', as suas faculdades mentais." (LURIA et al., 2007, p. 50). Assim, os alunos deveriam sintetizar as experiências históricas, econômicas, sociais, culturais, ideológicas, apreendidas no conto "Holocausto" e produzir um novo conto retratando um problema social. Para esta atividade, definimos como critério de análise:

1. Respeitou a estrutura de conto literário na escrita de seus textos;

2. Estabeleceu um problema social;

3. Utilizou as dimensões histórica, econômica, social, cultural, ideológica, de poder, política, estética, afetiva, ética, entre outras, no conteúdo do conto.

O primeiro critério de análise demonstrou que os textos deveriam ter a estrutura de um conto. Ao analisar os textos elaborados pela turma $\mathrm{B}$, percebemos que os alunos utilizaram como forma o texto informativo com linguagem não literária. Assim, entendemos que os alunos não compreenderam o conceito de conto e suas especificidades. No que se refere à ação docente, observamos que o professor B teve contato com a metodologia proposta somente no Grupo de Estudos e demonstrou grande preocupação em apropriar-se da forma apresentada, em alguns momentos fazendo até leituras de trechos do planejamento durante as aulas. A forma por si só não privilegia o processo de aprendizagem, tornando-se necessário a apropriação do conteúdo em sua totalidade. Neste sentido, percebemos também que o conteúdo conto, objeto específico da disciplina de Língua Portuguesa, nem sempre está apropriado em sua totalidade pelo professor para realizar a mediação do conhecimento.

\footnotetext{
2 Transcrição direta de aula realizada durante as intervenções.

${ }^{3}$ Refere-se ao momento da catarse, em que o professor propõe uma avaliação do conteúdo conforme as dimensões estudadas, a fim de que o aluno possa expressar a síntese alcançada. (GASPARIN, 2012).
} 
Ao defender que cabe à educação escolar um tipo específico de conhecimento, os conhecimentos clássicos, o trabalho educativo não pode simplesmente limitar-se a uma forma específica de fazer em sala de aula, mas conscientizar-se quanto à própria natureza dos conteúdos representativos da máxima conquista cultural e científica da humanidade. Viabilizar formas adequadas para a apropriação dos elementos culturais é uma tarefa que requer do professor uma clareza sobre o que justifica a concepção dos conteúdos clássicos. (DUARTE, 2015; SAVIANI, 2015).

Os conteúdos vislumbrados pela Pedagogia Histórico-Crítica se identificam com os conteúdos universais, que representam a máxima conquista alcançada pela humanidade, uma apropriação pela qual, torna-se possível ao trabalho educativo produzir direta e intencionalmente o que há de mais humano na história do homem, sua produção histórica e cultural. Esta apropriação pode ser demonstrada pelo aluno por meio de um novo posicionamento frente ao conteúdo, expressando o conteúdo como uma expressão histórica, social, política, uma nova totalidade do conhecimento. (GASPARIN, 2012).

Neste sentido, serão tomados como objeto de análise os textos elaborados pela turma A. $\mathrm{Na}$ data da produção estiveram presentes vinte e três alunos, sendo que vinte e um utilizaram o formato conto e levantaram um problema vivenciado na sociedade, expressando diversas dimensões ao longo de sua escrita. Um texto não foi analisado por estar ilegível, e outro, por não ter participado das aulas anteriores, e assim, não levantou problemas sociais durante a elaboração do conto.

Os problemas levantados pelos alunos no decorrer dos contos demonstram sentimentos vivenciados na realidade concreta, como medo, solidão, angústia, insegurança, indiferença, entre outros. Para análise das dimensões abordadas, organizou-se um quadro, estabelecendo para cada dimensão, o trecho no qual o aluno buscou evidenciar.

Tabela 1: Trechos das dimensões encontradas nos contos produzidos pelos alunos

\begin{tabular}{|c|}
\hline Afetiva/Psicológica \\
\hline $\begin{array}{l}\text { 1. Minha vida é baseada em solidão, tristeza, medo, falta de amor, falta de um próximo. } \\
\text { Sou um jovem solitário [...]. (A1) }\end{array}$ \\
\hline A morte está mais perto que posso sentir. (A2) \\
\hline As lembranças que veem em minha mente, os choros que ainda escuto, os gritos de \\
\hline socorro que entram na minha cabeça, desde aquela noite, a esc \\
\hline não brilha mais para mim, o sorriso saiu do meu rosto. (A4) \\
\hline Chorando com dores, aflito, numa solidão cheia de desespero. (A5) \\
\hline Meu mundo foi parando lentamente, até que um dia ele parou por completo e a morte \\
\hline me alcançou. (A6) \\
\hline Cada passo que davam em minha direção sentia a dor forte no coração. (A8) \\
\hline $\begin{array}{l}\text { 7. Comecei a ficar com raiva, então joguei o livro no fogo, depois foi o jornal, a revista, } \\
\text { piquei as folhas. (A9) }\end{array}$ \\
\hline $\begin{array}{l}\text { 8. O que sentia era como uma grande ferida sem cura. [...]. A família dava força para lutar } \\
\text { e agora que perdeu o que resta é se juntar a eles. (A10) }\end{array}$ \\
\hline $\begin{array}{l}\text { 9. Ah... Se pudesse voltar a ser criança, fugir dessa solidão que é crescer, não ter } \\
\text { responsabilidades, poder ficar no colo da mamãe. (A11) }\end{array}$ \\
\hline $\begin{array}{l}\text { 10. Engolindo a dor e ficando quietos, eles continuavam acreditando que um sonho era } \\
\text { possível. (A14) }\end{array}$ \\
\hline $\begin{array}{l}\text { 11. Eu olhei para o lado e escutei um gemido, era uma mulher, tentei ajudá-la, mas ela estava } \\
\text { muito machucada, ela deu um último suspiro e morreu. (A16) }\end{array}$ \\
\hline
\end{tabular}




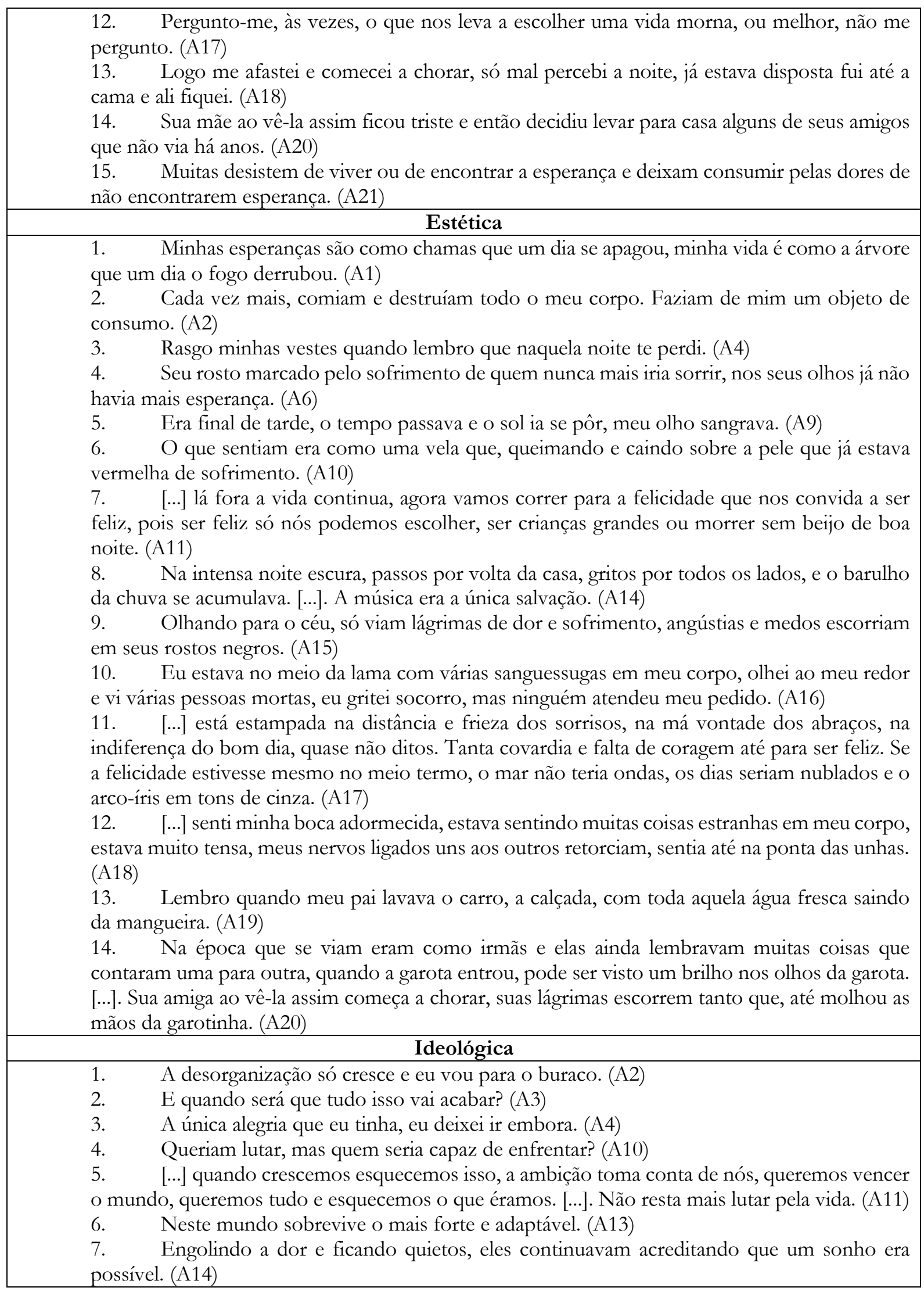




\begin{tabular}{|c|}
\hline $\begin{array}{l}\text { 8. Será que ninguém vê? Mães feitas como escravas, sendo obrigadas a ficar sem seus filhos, } \\
\text { homens brutos sem dó e em piedade, puxando aquelas crianças dos braços de suas mães. (A15) } \\
9 . \quad \text { Sei que fui tolo por ignorar tudo isso, estou velho e enfraquecido, sem cabelos, doente } \\
\text { com problemas renais por beber pouca água, sei que meu fim está próximo e que para mim já é } \\
\text { tarde para se preocupar. (A19) } \\
\text { 10. Principalmente num mundo onde os valores foram perdidos, esperança foi escondida e } \\
\text { a paz foi roubada de muitas pessoas. (A21) }\end{array}$ \\
\hline Histórica \\
\hline $\begin{array}{l}\text { 1. O que resta é varrer todas as cinzas marcadas pela rebeldia de um povo racista de origem } \\
\text { militar. (A2) } \\
\text { 2. Dias de Glória, dias de derrota. Para algumas cidades motivos de alegria e espírito } \\
\text { natalino, para Mariana não. A barragem se rompeu, a cidade está destruída, casas totalmente } \\
\text { cheias de lama, sonhos acabados. (A3) } \\
\text { 3. Vi pessoas morrerem queimadas, pisoteadas, amassadas, presas com a esperança de } \\
\text { alguém salvá-las, sinto até hoje as queimaduras em meus braços. (A4) } \\
\text { 4. E quando a guerra acabou fui para casa sabendo que mesmo no último segundo você } \\
\text { tem que ter fé. (A8) } \\
5 . \quad \text {.... as pessoas não saiam mais, se trancavam como prisioneiros de sua própria vida. (A10) }\end{array}$ \\
\hline Social \\
\hline $\begin{array}{l}\text { 1. "[...] Confesso que tive certos momentos de inveja, pois as pessoas ao meu redor têm } \\
\text { medo de mim. [...] Eu inspirava fundo e quando expirava, as lágrimas rolavam em meu rosto, } \\
\text { pois eu estava cansado de ser desprezado, humilhado. (A1) } \\
2 . \quad \text { Estão ficando na cidade, a marca da vida de cada um, principalmente as lembranças } \\
\text { deixadas por cada um deles. (A2) } \\
\text { 3. Por que a sociedade em que vivemos tem que ser tão dividida entre o bem e o mal? Por } \\
\text { que em pleno século XXI, o mal insiste em prevalecer? (A7) } \\
4 . \quad \text { Na Cracolândia a vida é assim, por que vivem assim? Falta de oportunidade? Refeição } \\
\text { social? (A12) } \\
5 . \quad \text { Um pensamento idealista e generalizado, como se a injustiça fosse uma invenção } \\
\text { contemporânea e não algo que faz parte da própria natureza caótica da existência. (A13) } \\
6 . \quad \text { Gritos de mulheres desesperadas, crianças chorando e esperneando, as latidas de } \\
\text { cachorros raivosos e mais uma vez a sirene tocava. [...]. Sem poder se expressar e falar, eles } \\
\text { começaram a pensar e agir. (A14) } \\
7 . \quad \text { As manhãs sem sol, as noites frias e longas, crianças perdidas, mães aflitas. Crianças } \\
\text { machucadas, com fome, perdida nesse mundo, sujas pela lama, vivendo nessa escravidão. (A15) } \\
\text { 8. Lembro de quando era mais novo e usávamos a água abundantemente e de como as } \\
\text { pessoas ignoravam os alertas para economizar água. (A19) } \\
9 . \quad \text { [...] ela estava em uma grave depressão, vivia quieta e quase não falava, passava o dia } \\
\text { dentro de seu quarto, sua família fazia tudo para que ela melhorasse, mas a garotinha estava em } \\
\text { uma depressão tão grande. (A 20) } \\
\text { 10. A violência mundial tem corrompido o Mundo por todos os lugares e de todas as } \\
\text { maneiras, é com muita dor no meu coração, trincando de decepção com tanta tortura, ao ver } \\
\text { tanta desigualdade que virando a esquina de casa já me deparo com ela e muitas outras. (A21) } \\
\end{array}$ \\
\hline De poder \\
\hline $\begin{array}{l}\text { 1. Da janela via famílias se divertindo, sorrindo. Confesso que tive certos momentos de } \\
\text { inveja. (A1) } \\
\text { 2. O que resta acontecer comigo e aqueles que estão marcados [...] é ser empurrado pela } \\
\text { mão militar na escuridão das trevas da noite. [...] vejo ossos consumidos pelo fogo que destruiu } \\
\text { milhares de pessoas. (A2) } \\
\text { 3. Sabendo que tudo poderia desabar e não tomaram providências. (A3) }\end{array}$ \\
\hline
\end{tabular}


4. Naquele momento o medo, a insegurança e revolta invadiram todos os meus sentidos, fazendo com que minhas pernas travassem e minha voz se calasse. (A6)

5. Abro os olhos novamente e me deparo empunhando uma arma na mão. [...]. (A8)

6. Um pensamento obcecado por encontrar e criar vítima, coitados, como se num momento de pré-civilização todos tivessem acesso igualitário a uma justiça plena e infalível. (A13)

7. Engolindo a dor e ficando quietos, eles continuavam acreditando que um sonho era possível. Vendo os próximos, ou alguém importante sendo tirado de você. O que podiam fazer? (A14)

8. Será que ninguém vê? Mães feitas como escravas, sendo obrigadas a ficar sem seus filhos, homens brutos sem dó e em piedade, puxando aquelas crianças dos braços de suas mães. (A15)

9. E com tantas pessoas que só pensam em si mesmas, olham para o próprio umbigo, vivem em seus mundinhos tecnológicos e suas vidinhas perfeitas e se esquecem de estender a mão para o próximo e não descem do "salto" onde estão para abrirem os seus olhos para a realidade. (A21)

Fonte: A autora, 2017.

As dimensões destacadas possibilitam vincular o conteúdo à realidade social mais ampla. São questões que se apoiam na dimensão social, política, ideológica, histórica, psicológica, entre outros. Elementos estes, que viabilizam a apropriação pelas camadas populares de ferramentas culturais necessárias como ser social concreto (SAVIANI, 2008; 2015; GASPARIN, 2012). A dimensão afetiva é a mais retratada nas produções dos alunos, enfatizam sentimentos de solidão, tristeza, medo, falta de amor, de um próximo, morte, lembranças, aflição, raiva, força e esperança. Estes sentimentos registrados nas produções dos alunos estão presentes no contexto da ditadura militar e no decorrer do conto "Holocausto", em que o personagem retrata incessantemente a angústia vivenciada:

Estendi as mãos e, quando olhei em volta, havia mais doze pares de mãos estendidas ao lado das minhas. Os doze pares de mãos estavam cheios de feridas úmidas e violáceas. Todos viram ao mesmo tempo, mas ninguém gritou. Eu gostaria de ter conseguido olhá-los no fundo dos olhos, de ter visto neles qualquer coisa como compaixão, paciência, tolerância, ou mesmo amizade, quem sabe amor. (ABREU, 1996, p. 7).

O conto buscou, neste sentido, exercer uma influência didática sobre o leitor proporcionando aos alunos uma vivência estética, em que o sensível e o inteligível se uniram em uma nova percepção, na qual compreender não se trata de reproduzir um reflexo exato, passivo, uma duplicação da vivência do outro em mim, mas sim apropriar-se da vivência do outro, que somada às vivências e aos valores do leitor possibilitam uma nova percepção. (BAKHTIN, 1997).

A compreensão da dimensão afetiva refere-se à apropriação do conteúdo apresentado, onde por meio das experiências e sentidos do outro, o sujeito pode conscientizar-se e manifestar aquelas emoções e sentimentos do lado de fora da vida do outro, em que "[...] reconstrói o homem interior por inteiro, em categorias estéticas compassivas, para uma nova existência, numa nova dimensão do mundo." (BAKHTIN, 1997, p. 117).

No que se refere à dimensão estética abordada pelos alunos, observamos uma constante vinculação das experiências presentes no conto com aquelas vivenciadas no contexto cultural dos alunos, em que por meio da dor, do sofrimento do outro, se estabelece relações com o sofrimento do mundo atual, do cotidiano, elevando-se da particularidade individual para a generalização estética. Ao tratar do potencial criador do homem, Lukács (1970) afirma que esta transformação 
ocorre como consequência do contato com a realidade objetiva, como consequência do esforço humano em reproduzir esta realidade de modo profundo e verdadeiro.

A sensibilidade estética cria no ser humano novas possibilidades de ser, pensar, agir, apreender e sentir o mundo a partir das experiências do outro. As transformações viabilizadas pelas fruições estéticas podem possibilitar uma percepção totalizante da realidade, elevando-se à esfera da consciência pela superação do cotidiano. Neste sentido, o texto produzido pelos alunos constitui-se de um elo da comunicação verbal, pois se relaciona com o conto lido, mas ao mesmo tempo com outras obras e com as vivências dos alunos. (BAKHTIN, 1997).

A dimensão ideológica apresentada pelo narrador é demonstrada também nos textos produzidos pelos alunos, por meio de situações que justificam de certa maneira, a ordem social vigente, os próprios problemas sociais. No conto, o narrador expõe ainda que "Talvez apenas afaste esses braços e pernas que enredam meus movimentos e faça o primeiro gesto em direção ao fogo." (ABREU, 1996, p. 8-9). Esta conformação do homem frente às situações postas, também está presente na realidade atual, na falta de reconhecimento do homem frente ao seu processo de criação, na perda dos sentidos humanos em uma sociedade fragmentada, ou como enfatizou Marx (2004) na perda da essência do próprio "ser".

Contraditoriamente, na produção dos alunos, a dimensão social aparece como denúncia, necessidade de uma transformação, mas também como conformação e falta de possibilidades. Verifica-se que o tema mais apresentado pelos alunos, refere-se à injustiça, ou seja, um problema social presente no conto, mas também vivenciado constantemente pelas camadas populares pela "[...] injustiça decorrente de condições desiguais" (MARX, 1996, p. 119).

O conto "Holocausto" não faz menção direta ao período da Ditadura Militar, mas, relata situações que podem ser interpretadas pelo leitor, como por exemplo, um cativeiro: "A casa, os outros. Quando percebi que eles existiam — e eram muitos, doze, treze comigo — já meu corpo estava completamente tomado. E temi que me expulsassem". (ABREU, 1996, p. 6-7).

Ao longo da leitura e análise, os alunos puderam compreender o caráter histórico da literatura e do conto em estudo, e com isso, apropriar-se desta dimensão em suas produções, relatando o sofrimento das guerras, dos cativeiros e até mesmo o sofrimento das pessoas no desastre ocorrido em Mariana, Minas Gerais. Assim, "O sentido real de cada palavra é determinado, no fim das contas, por toda a riqueza dos momentos existentes na consciência e relacionados aquilo que está expresso por uma determinada palavra." (VIGOTSKI, 2001, p. 466).

As relações estabelecidas com o conto estão vinculadas aos grandes problemas sociais, que somadas às percepções individuais, instigam o leitor a tomar para si o social e o histórico como meio para analisar os fenômenos da realidade atual de forma cada vez mais consciente. É esta consciência que faz com que os alunos apontem uma dimensão de poder em suas palavras, denunciando as diferenças sociais vivenciadas, que podem ser ouvidas como um pedido de socorro, em que muitos passam despercebidos neste mundo atual, onde as necessidades alheias são esquecidas em pro da busca do bem e da sobrevivência individual, em que o homem se individualiza, renegando sua essência como gênero humano, de construção social e coletiva.

\section{CONSIDERAÇÕES FINAIS}

O objetivo principal da pesquisa foi analisar se a ação docente, fundamentada no Materialismo Histórico-Dialético e na Pedagogia Histórico-Crítica, é fundamental para o desenvolvimento do ato de ler na Educação Básica. Os resultados apontaram ser este um encaminhamento pertinente para o desenvolvimento do ato de ler, tornando-se uma práxis fundamental para aqueles que buscam contribuir para a formação humana. 
O estudo do conto "Holocausto" à luz da Pedagogia Histórico-Crítica possibilitou aos alunos, reconhecer-se como parte da história humana, vivenciar o contexto do outro e, com isso, refinar suas sensações e percepções da realidade circundante. Este movimento realizado pelos alunos interfere tanto no desenvolvimento de suas funções psíquicas, na sua formação individual, como na sua constituição como ser social. O conto por si só não tem o poder de modificar a realidade social, mas pode trazer ao sujeito um repensar sobre a história da humanidade e seu comportamento frente à continuidade desta grande história, onde ao revelar este mundo, pode possibilitar ao leitor a construção de uma nova história, conforme observado nas produções dos alunos.

Entendemos que o trabalho com as dimensões viabiliza a percepção do homem como sujeito histórico e social, que tem seu desenvolvimento marcado por questões sociais, políticas, culturais, afetivas, estéticas. Enfatizamos, porém, que as dimensões são instrumentos de mediação da forma didática, porém elas por si só, não viabilizam o desenvolvimento do aluno, que está atrelado a um processo de apropriação de todo o contexto, ou seja, da união entre forma e conteúdo do trabalho educativo.

Ao efetivar este processo, a Pedagogia Histórico-Crítica pode vislumbrar um efeito catártico no aluno, movendo as suas perspectivas individuais para a apropriação das formas mais ricas do gênero humano. Manifestando-se como conhecimento clássico, este saber pode tornar-se mediador na prática social dos homens, na luta contra a alienação da consciência humana, ou seja, o aluno não se apropriou somente de um conteúdo curricular, mas de um instrumento de consciência individual e social na construção de sua realidade.

\section{REFERÊNCIAS}

ABREU, Caio Fernando. Holocausto. In: ABREU, Caio Fernando. Pedras de Calcutá. São Paulo: Companhia das Letras, $1996 . \quad$ Disponível em http://www.cyvjosealencar.seed.pr.gov.br/redeescola/escolas/26/700/16/arquivos/File/Livros $\angle$ Caio $\% 20$ Fernando $\% 20$ Abreu/Pedras $\% 20$ de\%20Calcuta.pdf. Acesso em 2 jun. 2015.

AZEVEDO, Ricardo. Dezenove poemas desengonçados. São Paulo: Ática, 1998.

BAKHTIN, Mikhail. Estética da criação verbal. São Paulo: Martins Fontes, 1997.

DUARTE, Newton. A importância da concepção de mundo para a educação escolar: porque a Pedagogia Histórico-Crítica não endossa o silêncio de Wittgenstein. Germinal: Marxismo e Educação em Debate, Salvador, v. 7 n. 1, p. 8-25, jun. 2015.

GASPARIN, João Luiz. Uma didática para a pedagogia histórico-crítica. Campinas: Autores Associados, 2012.

LUKÁCS, Georg. Introdução a uma estética marxista: sobre a categoria da particularidade. Tradução de Carlos Nelson Coutinho e Leandro Konder. 2. ed. Rio de Janeiro: Civilização Brasileira, 1970.

LURIA, Aleksandr Romanovich; LEONTIEV, Alexis N.; VIGOTSKY, Lev Semenovich. Psicologia e Pedagogia: Bases Psicológicas da Aprendizagem e do Desenvolvimento. 4. ed. São Paulo: Centauro, 2007.

MANGUEL, Alberto. Uma história da leitura. São Paulo: Cia. das Letras, 1997.

MARX, Karl. O Capital: crítica da economia política. Livro 1. V. 1. Tomo 2. (Os economistas). Tradução por Regis Barbosa e Flávio R. Kothe. Ed. Nova Cultura Ltda., 1996.

MARX, Karl. Manuscritos econômico-filosóficos. Tradução de Jesus Ranieri. São Paulo: Boitempo Editorial, 2004. 
OLIVEIRA, Betty; DUARTE, Newton. A socialização do saber escolar. São Paulo: Cortez: Autores Associados, 1986.

SAVIANI, Dermeval. Escola e democracia. Campinas: Autores Associados, 2008. (Coleção educação contemporânea).

SAVIANI, Dermeval. Pedagogia histórico-crítica: primeiras aproximações. 11. ed. Campinas: Autores Associados, 2011.

SAVIANI, Dermeval. O conceito dialético de mediação na pedagogia histórico-crítica em intermediação com a psicologia histórico-cultural. Germinal: Marxismo e Educação em Debate, Salvador, v. 7 n. 1, p. 26-43, jun. 2015. Disponível em http://dx.doi.org/10.9771/gmed.v7i1.13575.

VIGOTSKI, Lev Semenovich. A construção do pensamento e da linguagem. Tradução de Paulo Bezerra. São Paulo: Martins Fontes, 2001.

Submetido em abril de 2019

Aprovado em maio de 2020

\section{Informações das autoras}

Geuciane Felipe Guerim Fernandes

Mestre e doutoranda em educação pela Universidade Estadual de Londrina (UEL). Professora

colaboradora na Universidade Estadual do Norte do Paraná (UENP), campus de Cornélio Procópio, curso de Pedagogia.

E-mail:geu tc@hotmail.com

ORCID: https://orcid.org/0000-0002-8033-6561

Link Lattes: http://lattes.cnpq.br/1609923783080279

Sandra Aparecida Pires Franco

Professora Associada do Departamento de Educação da Universidade Estadual de Londrina (UEL) e professora do Programa de Pós-Graduação em Educação (UEL).

E-mail: sandrafranco26@hotmail.com

ORCID: http://orcid.org/0000-0002-7205-744X

Link Lattes: http://lattes.cnpq.br/4775777293922801 